\title{
Origin of the Electrochemical Stability of Aqueous Concentrated Electrolyte Solutions
}

\section{$\operatorname{AUTHOR}(S)$ :}

Yokoyama, Yuko; Fukutsuka, Tomokazu; Miyazaki, Kohei; Abe, Takeshi

\section{CITATION:}

Yokoyama, Yuko ...[et al]. Origin of the Electrochemical Stability of Aqueous Concentrated Electrolyte Solutions. Journal of the Electrochemical Society 2018, 165(14): A3299-A3303

\section{ISSUE DATE:}

2018-10

URL:

http://hdl.handle.net/2433/235003

\section{RIGHT:}

(c) The Author(s) 2018. Published by ECS. This is an open access article distributed under the terms of the Creative Commons Attribution 4.0 License (CC BY, http://creativecommons.org/licenses/by/4.0/), which permits unrestricted reuse of the work in any medium, provided the original work is properly cited. 


\title{
Origin of the Electrochemical Stability of Aqueous Concentrated Electrolyte Solutions
}

\author{
Yuko Yokoyama, Tomokazu Fukutsuka, (i)* Kohei Miyazaki, ${ }^{*}{ }^{*, z}$ and Takeshi Abe \\ Graduate School of Engineering, Kyoto University, Nishikyo-ku, Kyoto 615-8510, Japan
}

\begin{abstract}
Aqueous solutions have attracted considerable attention for use in aqueous-based energy-conversion devices such as aqueous lithium-ion batteries. While aqueous solutions have some desirable properties as electrolyte solutions, one drawback is the narrow potential window of water due to the electrolysis reactions of water (oxygen/hydrogen evolution reaction, OER/HER). Recently, it has been reported that the potential windows were expanded in concentrated electrolyte solutions. In this study, we investigated the potential windows in aqueous concentrated electrolyte solutions with various salts at different concentrations. A neutral $\mathrm{pH}$ solution with the lowest water concentration showed the largest potential window, and the potential windows were not affected by the electrolyte salts. In addition, we observed an asymmetric expansion of potential windows: the upper potential limits were shifted more than the lower limits. This can be explained by the local $\mathrm{pH}$ change in the vicinity of electrodes caused by OER/HER and the decrease in the rate of OER due to the reduced water concentrations.

(C) The Author(s) 2018. Published by ECS. This is an open access article distributed under the terms of the Creative Commons Attribution 4.0 License (CC BY, http://creativecommons.org/licenses/by/4.0/), which permits unrestricted reuse of the work in any medium, provided the original work is properly cited. [DOI: $10.1149 / 2.0491814$ jes]

(cc) BY
\end{abstract}

Manuscript submitted August 29, 2018; revised manuscript received October 10, 2018. Published October 23, 2018

The electrochemical stability of an electrolyte solution, its socalled "potential window", is simply determined by the oxidative potential and reductive potential of the solvent, if solutes dissolved in the electrolyte solution are electrochemically stable within the potential window of the solvent. Water is the most conventional solvent in the field of electrochemistry, and its potential window is as narrow as $1.23 \mathrm{~V}$, thermodynamically. Practically, however, the oxygen evolution reaction (OER) and hydrogen evolution reaction (HER) need certain overpotentials, which extends the potential windows of aqueous solutions. For example, lead-acid rechargeable batteries have a working voltage of $2 \mathrm{~V}$ in a sulfuric acid solution. This large voltage is due to the overpotentials of OER and HER on a positive electrode material $\left(\mathrm{PbO}_{2}\right)$ and a negative electrode material $(\mathrm{Pb})$, respectively. ${ }^{1,2}$ Besides the catalytic activities of the electrode materials, ${ }^{1,2}$ the properties of aqueous solutions such as hydration structures and salt concentrations also affect the potential window.

Recently, aqueous rechargeable lithium batteries (ARLBs) have attracted much attention due to their low cost and safety. ${ }^{3,4}$ However, the working voltage of ARLBs is limited to below $1.5 \mathrm{~V}$ due to the narrow potential window of water. ${ }^{5-14}$ Recently, a few papers have discussed the potential window of concentrated aqueous solutions with neutral $\mathrm{pH}^{15-19}$ Suo et al. reported that saturated $21 \mathrm{~mol} \mathrm{~kg}^{-1}$ lithium bis(trifluoromethanesulfonyl)amide (LiTFSA) aqueous solution exhibited a wide potential window of ca. $3.0 \mathrm{~V} .{ }^{15}$ In addition, we showed that a high potential positive electrode material in lithium-ion batteries, $\mathrm{LiNi}_{0.5} \mathrm{Mn}_{1.5} \mathrm{O}_{4}$, could work in a saturated sodium propane1,3-disulfonate (PDSS) aqueous solution. ${ }^{18}$ The reaction potential of $\mathrm{LiNi}_{0.5} \mathrm{Mn}_{1.5} \mathrm{O}_{4}$ is $4.7 \mathrm{~V}$ (vs. $\mathrm{Li}^{+} / \mathrm{Li}$ ), which is $0.9 \mathrm{~V}$ higher than the upper limit of the potential window of water. These results indicate that the electrolyte concentration affects the potential windows of water, but the underlying mechanism has not been sufficiently clarified. One explanation for why it is difficult to consider the concentrated solution theoretically is because the properties of the solutions are far beyond what we see in an ideal solution.

In addition, the influence of $\mathrm{pH}$ on the potential window is also controversial. The potential window (the potential difference between the upper and lower limits) should, in principle, be independent of $\mathrm{pH}$, but it is actually affected by the $\mathrm{pH}$ of the solution. For example, Wessells et al. measured the electrode potential at a constant leakage current density of $50 \mu \mathrm{A} \mathrm{cm}$ cm $^{-2}$ and observed a maximum potential difference between OER and HER at $\mathrm{pH} 7 .{ }^{20}$ However, there are still fundamental unanswered questions regarding the $\mathrm{pH}$-dependence of the potential window of water.

\footnotetext{
*Electrochemical Society Member.

${ }^{\mathrm{z} E}$-mail: myzkohei@elech.kuic.kyoto-u.ac.jp
}

In this study, the potential window of concentrated electrolyte solutions with neutral $\mathrm{pH}$ and the expansion of the potential window were investigated from the viewpoint of the local $\mathrm{pH}$ change and water concentration. Previously, Kuhn and Chan emphasized the importance of the $\mathrm{pH}$ change in the vicinity of electrodes in metal finishing and corrosion, in association with OER/HER ${ }^{21}$ However, the local $\mathrm{pH}$ change has been overlooked in discussions of the potential window of water. Here, we shed light on the dependence of the potential window of water on local $\mathrm{pH}$ changes and water concentrations.

\section{Experimental}

Materials.-As electrolyte salts, $\mathrm{NaClO}_{4}$ (Strem Chemicals, Inc., 99\%), $\mathrm{NaNO}_{3}$ (Nacalai Tesque Co., Ltd., 99.0\%), disodium propane-1,3-disulfonate (PDSS; Tosoh Organic Chemical Co., Ltd.), $\mathrm{LiNO}_{3}$ (Nacalai Tesque Co., Ltd., 98.0\%), lithium bis(trifluoromethanesulfonyl)amide (LiTFSA; Kishida Chemical Co., Ltd., 99.9\%), $\mathrm{H}_{2} \mathrm{SO}_{4}$ (Nacalai Tesque Co., Ltd., 97.0\%), $\mathrm{HClO}_{4}$ (Tama Chemicals Co., Ltd., 70.0\%), $\mathrm{H}_{3} \mathrm{PO}_{4}$ (Nacalai Tesque Co., Ltd., $85.0 \%$ ) and $\mathrm{NaOH}$ (Nacalai Tesque Co., Ltd., 97.0\%) were used without further purification. Electrolyte solutions were prepared with deionized water. The concentrations of the electrolyte solutions are shown in Table I. Using a neutral $\mathrm{pH}$ salt, two solutions were prepared: $1 \mathrm{~mol} \mathrm{dm}^{-3}(\mathrm{M})$ and nearly saturated. To standardize the concentration of cations, the concentrations of PDSS, $\mathrm{H}_{2} \mathrm{SO}_{4}$ and $\mathrm{H}_{3} \mathrm{PO}_{4}$ were set to $0.5,0.5$ and $0.33 \mathrm{M}$, respectively. In addition, $0.1 \mathrm{M} \mathrm{Na}^{-\mathrm{PO}_{4} \text { buffer }}$ solution $\left(\mathrm{pH}=6.6\right.$; mixture of $\mathrm{NaH}_{2} \mathrm{PO}_{4}$ and $\mathrm{Na}_{2} \mathrm{HPO}_{4}$, purchased from Nacalai Tesque Co., Ltd., 99.0\%) was also prepared in the same way as above to investigate the effect of the local $\mathrm{pH}$ on the potential window.

Physicochemical properties of electrolyte solutions.-The densities were evaluated with a $1 \mathrm{~cm}^{3}$ Ostwald pycnometer (Sansho Co., ltd), and water concentrations were evaluated by densities. Specific ion conductivities were evaluated with a two-electrode cell with $\mathrm{Pt}$ plates by AC impedance spectroscopy (VSP-300, Bio-Logic Science Instruments). Viscosities were measured by an automated micro viscometer (Anton $\mathrm{Paar} \mathrm{GmbH}$ ). The $\mathrm{pHs}$ were measured with a $\mathrm{pH}$ meter (D-52, Horiba, Ltd.). A pulsed ${ }^{1} \mathrm{H}$ NMR spectrometer $(13 \mathrm{MHz}$, Acorn Area, Xigo Nanotools) was used to measure spin-spin relaxation times $\left(T_{2}\right)$ of water in electrolyte solutions. Neutral $\mathrm{pH}$ solutions were used, except for PDSS which has $\mathrm{H}$ atom in the solute itself. For $T_{2}$ measurement, the Carr-Purcell-Meiboom-Gill (CPMG) method was used, which involves repeated $90^{\circ}, t, 180^{\circ}$ pulse sequences, where $t$ is the time interval between the two pulses. The 
Table I. Properties of the prepared solutions.

\begin{tabular}{|c|c|c|c|c|c|}
\hline & Water concentration/M & Specific conductivity $/ 10^{-3} \mathrm{~S} \mathrm{~cm}^{-1}$ & Viscosity $/ \mathrm{mPa} \mathrm{s}$ & $\mathrm{pH}$ & Spin-spin relaxation time $\left(T_{2}\right) / \mathrm{s}$ \\
\hline $1.0 \mathrm{M} \mathrm{NaClO}_{4}$ & 54.0 & 78 & 0.93 & 6.6 & 2.5 \\
\hline $9.0 \mathrm{M} \mathrm{NaClO}_{4}$ & 32.9 & 115 & 7.3 & 7.1 & 1.5 \\
\hline $0.50 \mathrm{M}$ PDSS & 53.4 & 56 & 1.2 & 6.8 & - \\
\hline $1.0 \mathrm{M} \mathrm{NaNO}_{3}$ & 54.7 & 76 & 0.95 & 5.9 & 2.5 \\
\hline 7.6 $\mathrm{M} \mathrm{NaNO}_{3}$ & 42.0 & 200 & 2.5 & 6.3 & 2.2 \\
\hline $1.0 \mathrm{M} \mathrm{LiNO}_{3}$ & 54.3 & 71 & 0.99 & 6.6 & 2.6 \\
\hline 5.2 M LiTFSA & 14.4 & 10 & 51 & 6.0 & 0.47 \\
\hline $0.50 \mathrm{M} \mathrm{H}_{2} \mathrm{SO}_{4}$ & 54.4 & 227 & 0.98 & - & - \\
\hline $1.0 \mathrm{M} \mathrm{HClO}_{4}$ & 53.8 & 342 & 0.86 & - & - \\
\hline $0.33 \mathrm{M} \mathrm{H}_{3} \mathrm{PO}_{4}$ & 55.5 & 25 & 0.96 & - & - \\
\hline $1.0 \mathrm{M} \mathrm{NaOH}$ & 56.6 & 194 & 1.1 & - & - \\
\hline
\end{tabular}

water vapor pressures were measured with an absolute pressure gauge (AVG-300C11, Okano Works, LTD.).

Electrochemical measurements. - To estimate the potential windows, cyclic voltammetry was performed with a three-electrode cell by an ALS/CHI Electrochemical Analyzer (Model 600A, BAS Inc.). The cell was composed of a Pt plate and $\mathrm{Pt}$ wire as working and counter electrodes, respectively. As a reference electrode, saturated $\mathrm{Ag} / \mathrm{AgCl}$ was used for neutral $\mathrm{pH}$ electrolyte solutions, and a reversible hydrogen electrode (RHE) was used for acidic or alkaline electrolyte solutions. Prior to each cyclic voltammetry, electrolyte solutions were thoroughly deaerated with Ar gas for at least $30 \mathrm{~min}$. The sweep rate in cyclic voltammetry was $1 \mathrm{mV} \mathrm{s}^{-1}$. Each measurement was carried out at a constant temperature of $25^{\circ} \mathrm{C}$. The current density was calculated by dividing the measured current by the geometrical area of the Pt surface.

\section{Results}

Physicochemical properties of the electrolyte solutions are listed in Table I. No clear correlation was observed between the specific ion conductivity or the viscosity and the water concentration. However, $T_{2}$ decreased with a decrease in the water concentration (Fig. 1). $T_{2}$ is sensitive to molecular motion and a decrease in $T_{2}$ means that there is an increase in solvated water, i.e., there is a decrease in free water. ${ }^{22}$ It should be noted here that $T_{2}$ is not directly related to the activity of water.

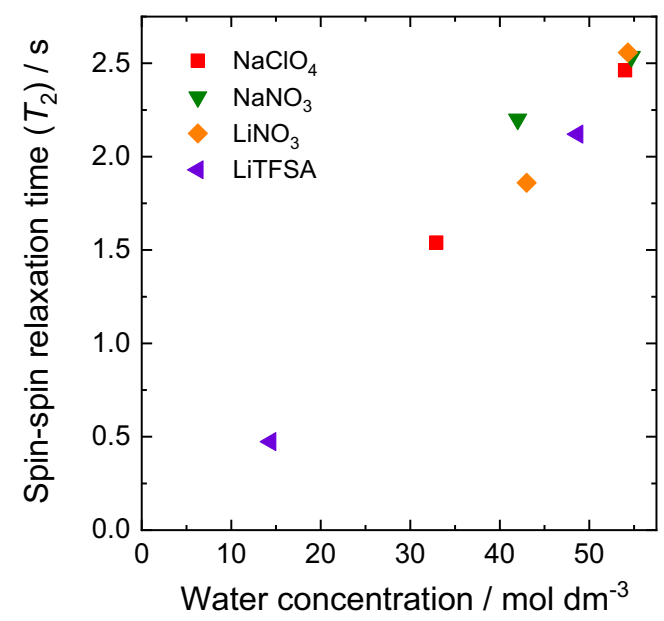

Figure 1. Spin-spin relaxation time $\left(T_{2}\right)$ of various salt solutions with various water concentrations.
Cyclic voltammograms (CVs) of Pt in neutral $\mathrm{pH}$ solutions without buffer capacity are shown in Fig. 2. In these electrolyte solutions, the right-hand side of the potential window is determined by the OER, and the left-hand side is determined by the HER. When we compared two solutions with different concentrations (1 M and saturated) of the same salt, the potential windows of saturated solutions were broader than those of $1 \mathrm{M}$ solutions. These windows were much wider than the thermodynamically expected value of $1.23 \mathrm{~V}$. Notably, the upper limits were more expanded than the lower limits in all solutions, indicating that the OER was much more suppressed than the HER in saturated solutions.

Cyclic voltammetry was also performed in $0.50 \mathrm{M} \mathrm{H}_{2} \mathrm{SO}_{4}, 1.0 \mathrm{M}$ $\mathrm{HClO}_{4}, 0.33 \mathrm{M} \mathrm{H}_{3} \mathrm{PO}_{4}$ and $1.0 \mathrm{M} \mathrm{NaOH}$. CVs are shown in Fig. 3 with a potential referenced to RHE. All solutions showed almost the same potential windows except for $\mathrm{NaOH}$. In $\mathrm{NaOH}$, the onset potential of the OER was lower than that in acid solutions. It is known that the oxidation potential of $\mathrm{OH}^{-}$is more negative than that of solvent water due to the difference in the reactivities of $\mathrm{OH}^{-}$and $\mathrm{H}_{2} \mathrm{O}$ on $\mathrm{Pt}^{23}$ Therefore, $\mathrm{NaOH}$ solution showed the lowest onset potential for the OER. Comprehensively, from Figs. 2 and 3, it was clarified

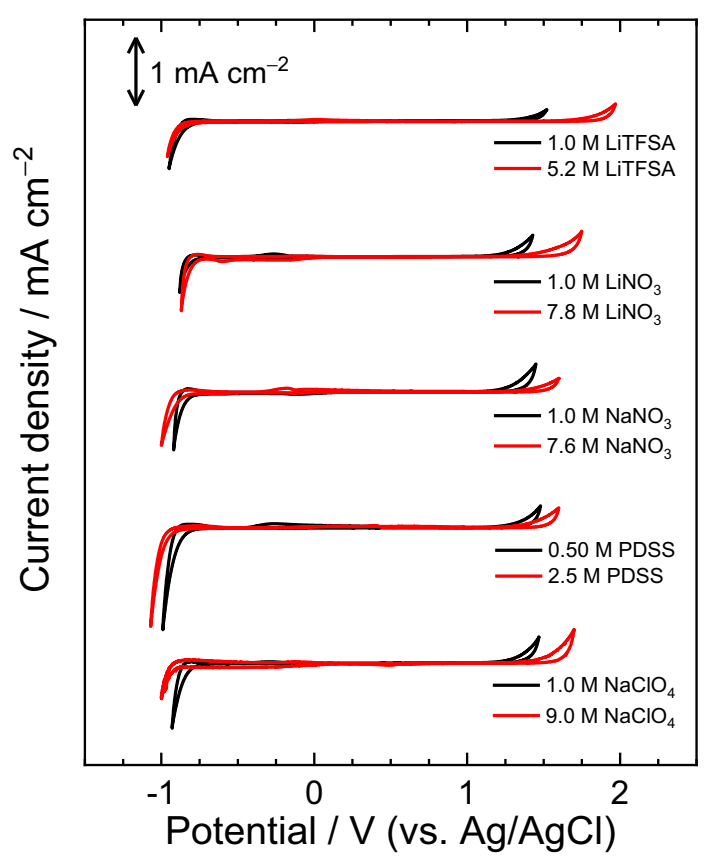

Figure 2. $\mathrm{CV}$ s of $\mathrm{Pt}$ in aqueous solution of $\mathrm{NaClO}_{4}, \mathrm{PDSS}, \mathrm{NaNO}_{3}, \mathrm{LiNO}_{3}$ and LiTFSA with 1.0 M-cation concentration (black line) and almost saturated concentration (red line). Sweep rate was $1 \mathrm{mV} \mathrm{s}^{-1}$. 


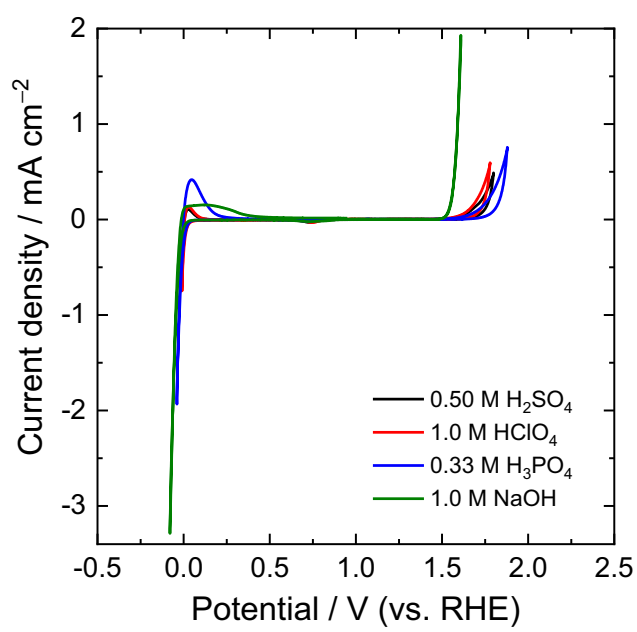

Figure 3. $\mathrm{CVs}$ of $\mathrm{Pt}$ in $0.50 \mathrm{M} \mathrm{H}_{2} \mathrm{SO}_{4}$ (black line), $1.0 \mathrm{M} \mathrm{HClO}_{4}$ (red line), $0.33 \mathrm{M} \mathrm{H}_{3} \mathrm{PO}_{4}$ (blue line) and $1.0 \mathrm{M} \mathrm{NaOH}$ (green line). Measurements were performed with RHE reference electrode. Sweep rate was $1 \mathrm{mV} \mathrm{s}^{-1}$.

that the potential windows in neutral $\mathrm{pH}$ electrolyte solution, even in $1 \mathrm{M}$ solution, were wider than those in acidic or alkaline electrolyte solutions.

Next, we focused on the water concentration, since the potential windows are determined by the water electrolysis reactions (OER and HER). The potential windows are shown in Fig. 4 as a function of the water concentrations. In this study, the onset potential of the OER/HER was defined when the current density was $\pm 0.1 \mathrm{~mA} \mathrm{~cm}^{-2}$ in CVs at $1 \mathrm{mV} \mathrm{s}^{-1}$. There are two clear tendencies in Fig. 4. First, the windows in neutral $\mathrm{pH}$ electrolyte solutions (closed symbols in Fig. 4) were obviously wider than those in acidic/alkaline electrolyte solutions (open symbols in Fig. 4), even at a dilute salt concentration (ca. $55 \mathrm{M}$ water concentration). The same trends were observed in $1 \mathrm{M} \mathrm{LiNO}_{3}$ aqueous solution, as reported by Wessells et al. ${ }^{20} \mathrm{Sec}-$ ond, the windows in neutral $\mathrm{pH}$ electrolyte solution (closed symbols in Fig. 4) were not affected by the kind of the electrolyte salt, but depended linearly on the water concentration. The windows were expanded when the water concentration decreased, i.e., the electrolyte salt concentrations increased.

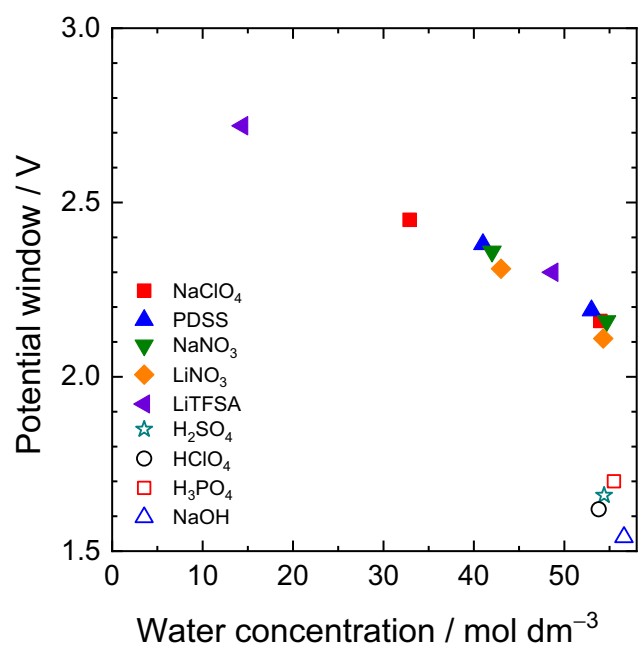

Figure 4. Potential window width dependence on water concentration. Onset potential of the OER/HER was defined when the current density was $\pm 0.1 \mathrm{~mA} \mathrm{~cm} \mathrm{~cm}^{-2}$ in CVs. Closed symbols denote neutral $\mathrm{pH}$ aqueous electrolyte solution, and open symbols denote acid/alkaline aqueous solutions.

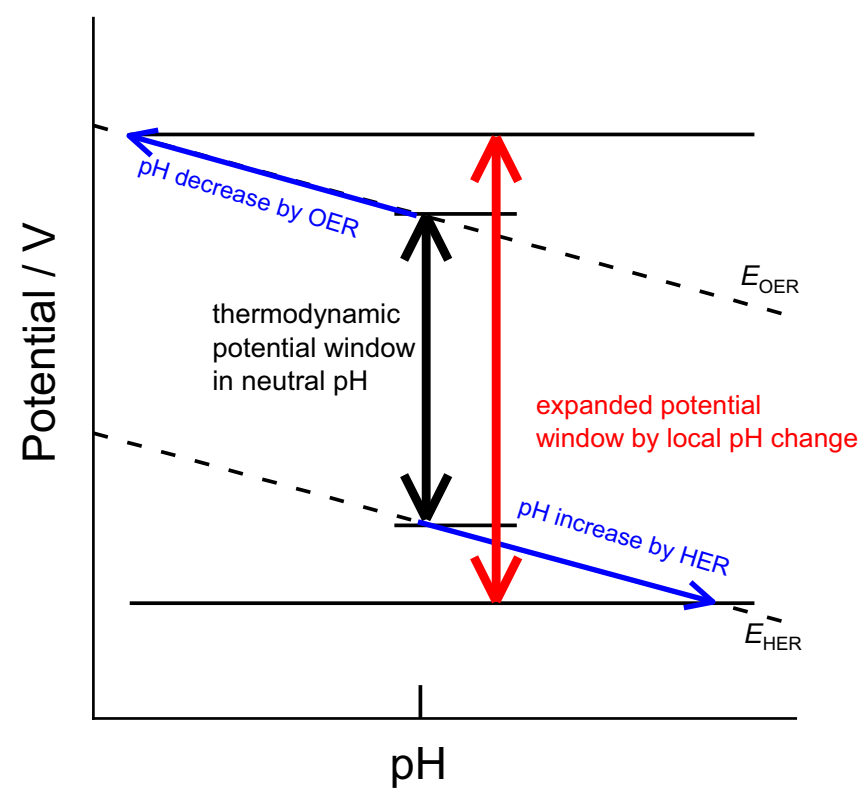

Figure 5. Oxygen/hydrogen evolution reaction potential change occurred by local $\mathrm{pH}$ change through Eqs. 3 and 4. The local $\mathrm{pH}$ near the electrode is decreased/increased by OER/HER, and by which reaction potential is increased/decreased.

\section{Discussion}

Effect of a local pH change on the potential window.-First, we consider why the potential windows in dilute neutral $\mathrm{pH}$ electrolyte solutions were wider than those in acidic/alkaline electrolyte solutions. The change in local $\mathrm{pH}$ in the vicinity of the electrodes can explain these wide potential windows in neutral $\mathrm{pH}$ electrolyte solutions. When OER/HER occurs at $\mathrm{pH}=7$, protons/hydroxide ions are formed by the following reactions;

$$
\begin{gathered}
2 \mathrm{H}_{2} \mathrm{O} \rightarrow \mathrm{O}_{2}+4 \mathrm{H}^{+}+4 \mathrm{e}^{-} \\
2 \mathrm{H}_{2} \mathrm{O}+2 \mathrm{e}^{-} \rightarrow \mathrm{H}_{2}+2 \mathrm{OH}^{-}
\end{gathered}
$$

In neutral $\mathrm{pH}$ solutions, the concentration of proton is low, ca. $10^{-7} \mathrm{M}$. Hence, in unbuffered neutral $\mathrm{pH}$ solutions, the local $\mathrm{pH}$ conditions in the vicinity of the electrodes change drastically to acid/alkaline as a result of OER/HER. According to the Nernst equation, the thermodynamic reaction potentials of OER and HER shift with the $\mathrm{pH}$ as follows, assuming that the water activity and fugacity of $\mathrm{H}_{2}$ and $\mathrm{O}_{2}$ are equal to unity;

$$
\begin{gathered}
E_{\mathrm{OER}}=E_{\mathrm{H}_{2} \mathrm{O} / \mathrm{O}_{2}}^{\circ}-2.303 \frac{R T}{F} \mathrm{pH} \\
E_{\mathrm{HER}}=E_{\mathrm{H}_{2} / \mathrm{H}_{2} \mathrm{O}}^{\circ}+2.303 \frac{R T}{F}(14-\mathrm{pH})
\end{gathered}
$$

where $E_{\mathrm{OER}}$ and $E_{\mathrm{HER}}$ are the reaction potentials of Eqs. 1 and 2, and $E_{\mathrm{H}_{2} \mathrm{O} / \mathrm{O}_{2}}^{\circ}$ and $E_{\mathrm{H}_{2} / \mathrm{H}_{2} \mathrm{O}}^{\circ}$ are standard reaction potentials of Eqs. 1 and 2, respectively. $R, T$, and $F$ are the gas constant, the absolute temperature, and the Faraday constant. According to Eqs. 3 and 4, $E_{\mathrm{OER}}$ and $E_{\mathrm{HER}}$ changed according to the $\mathrm{pH}$ value (Fig. 5). $E_{\mathrm{OER}}$ increases with decreasing $\mathrm{pH}$, and $E_{\mathrm{HER}}$ decreases with increasing $\mathrm{pH}$. Due to the changes in local $\mathrm{pH}, E_{\mathrm{OER}}$ and $E_{\mathrm{HER}}$ were shifted as indicated by the blue arrows (Fig. 5). As a result, the potential window was expanded by the local $\mathrm{pH}$ change. (Fig. 5, red arrow).

The influence of a local $\mathrm{pH}$ change on the potential windows was investigated by cyclic voltammetry in neutral $\mathrm{pH}$ solutions with a

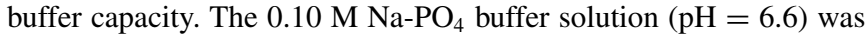
used to compare the results with the $1.0 \mathrm{M} \mathrm{NaClO}_{4}(\mathrm{pH}=6.6)$ solution 


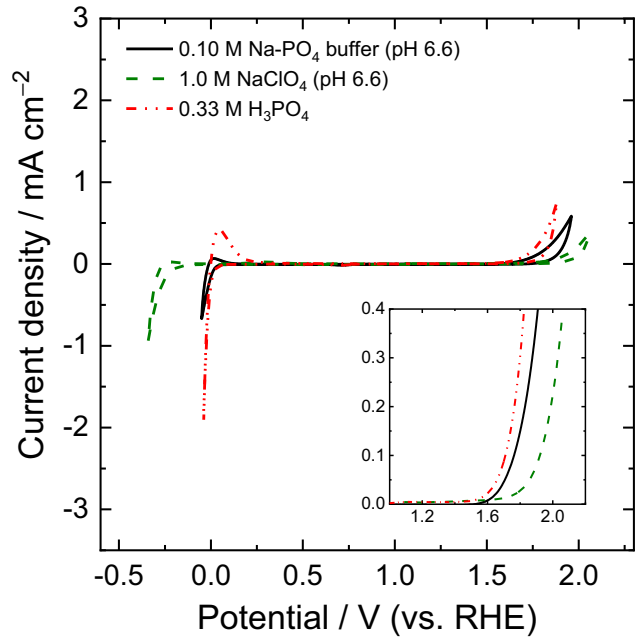

Figure 6. $\mathrm{CVs}$ of $\mathrm{Pt}$ in $0.1 \mathrm{M} \mathrm{Na}-\mathrm{PO}_{4}$ buffered solution (pH 6.6, black solid line). For comparison, $\mathrm{CVs}$ in $1.0 \mathrm{M} \mathrm{NaClO}_{4}(\mathrm{pH} 6.6$, green broken line) and $0.33 \mathrm{M} \mathrm{H}_{3} \mathrm{PO}_{4}$ (red dotted line) are also plotted here. Sweep rate was $1 \mathrm{mV} \mathrm{s}^{-1}$. For $\mathrm{NaClO}_{4}$ and $\mathrm{Na}-\mathrm{PO}_{4}$ buffered solution, the potential were converted into the RHE scale using their $\mathrm{pH}$, although they were measured with $\mathrm{Ag} / \mathrm{AgCl}$ as a reference electrode. The inset is a magnified view of the OER potential region.

without a buffer capacity. This buffer solution can suppress the local $\mathrm{pH}$ change in the vicinity of the electrodes via the following chemical reaction: 24

$$
\mathrm{H}_{2} \mathrm{PO}_{4}{ }^{-} \rightleftarrows \mathrm{H}^{+}+\mathrm{HPO}_{4}{ }^{2-} \quad \mathrm{p} K_{a}=6.43
$$

Therefore, the onset potentials of OER/HER in buffered neutral $\mathrm{pH}$ solutions should be the same as those in acid or alkaline solutions. $\mathrm{CV}$ in $0.10 \mathrm{M} \mathrm{Na}-\mathrm{PO}_{4}$ buffered solution is shown in Fig. 6, compared with $\mathrm{CV}$ s in $1.0 \mathrm{M} \mathrm{NaClO}_{4}$ and $0.33 \mathrm{M} \mathrm{H}_{3} \mathrm{PO}_{4}$. The inset in Fig. 6 is a magnified view of the OER potential region. Potentials in $0.1 \mathrm{M} \mathrm{Na}-\mathrm{PO}_{4}$ and $1.0 \mathrm{M} \mathrm{NaClO}_{4}$ were converted to the RHE scale using the respective pHs. The onset potentials of HER and OER in buffered solution were almost the same as those in $0.33 \mathrm{M} \mathrm{H}_{3} \mathrm{PO}_{4}$, as expected. Thus, the local $\mathrm{pH}$ change caused by OER/HER should be buffered in the buffered neutral $\mathrm{pH}$ solution, and the potential window was not expanded. Therefore, we conclude that the potential windows in unbuffered neutral $\mathrm{pH}$ solutions can be expanded by local $\mathrm{pH}$ changes.

Water concentration-dependence of the potential windows.Next, when we focus on the water concentration-dependence of the potential windows, we consider that the reduced water concentration in concentrated electrolyte solutions alters the OER/HER potentials and decreases the rate of water electrolysis reactions. In the case of concentrated electrolyte solutions, the activity of water can no longer be approximated as being equal to unity. Thus, Eqs. 3 and 4 should be rewritten as follows:

$$
\begin{array}{r}
E_{\mathrm{OER}}=E_{\mathrm{H}_{2} \mathrm{O} / \mathrm{O}_{2}}^{\circ}-2.303 \frac{R T}{F} \mathrm{pH}-\frac{R T}{4 F} \ln \left(a_{\mathrm{H}_{2} \mathrm{O}}\right)^{2} \\
E_{\mathrm{HER}}=E_{\mathrm{H}_{2} / \mathrm{H}_{2} \mathrm{O}}^{\circ}-2.303 \frac{R T}{F} \mathrm{pH}-\frac{R T}{2 F} \ln K
\end{array}
$$

where $a_{\mathrm{H}_{2} \mathrm{O}}$ is the activity of water, and $K$ is defined as the equilibrium constant of the reaction $\mathrm{H}_{2} \mathrm{O} \rightleftarrows \mathrm{H}^{+}+\mathrm{OH}^{-}$, when it is assumed that $a_{\mathrm{H}_{2} \mathrm{O}}$ is not constant. From Eq. 6 , the reaction potential of OER should be affected by the activity of water. When the water concentration decreases, the activity of water should also decrease, resulting in an increase in the reaction potential of OER. In addition to a shift in the reaction potential, the reaction rate will change with a decrease

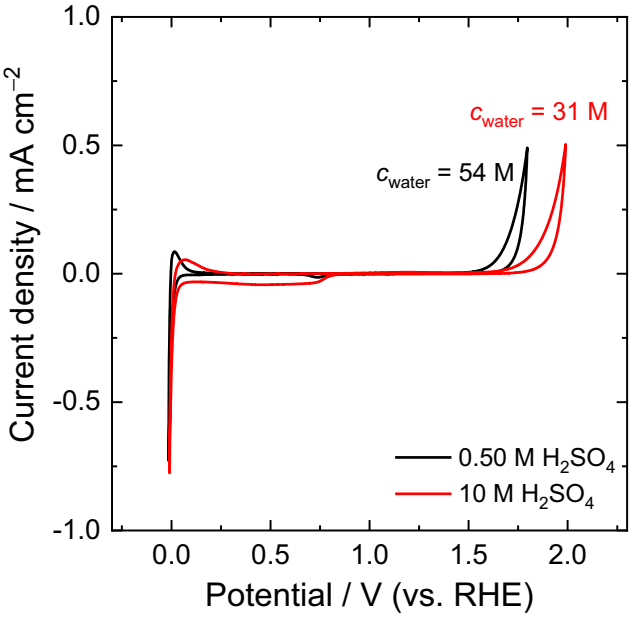

Figure 7. CVs of Pt in aqueous solution of $0.50 \mathrm{M}$ (black line) and $10 \mathrm{M}$ (red line) $\mathrm{H}_{2} \mathrm{SO}_{4}$. Sweep rate was $1 \mathrm{mV} \mathrm{s}^{-1}$.

in the water concentration. Assuming that HER on Pt electrodes is reversible, ${ }^{25-27}$ and migration is ignored, the current density $i$ can be described via Fick's first law; ${ }^{26}$

$$
i=-F\left(D_{\mathrm{H}^{+}} \nabla c_{\mathrm{H}^{+}}-D_{\mathrm{OH}^{-}} \nabla c_{\mathrm{OH}^{-}}\right)
$$

where $D_{\mathrm{j}}$ and $c_{\mathrm{j}}$ are the diffusion coefficient and the concentration of component j, respectively. Eqs. 7 and 8 do not include a term for the water concentration. Thus, there is little correlation between water concentration and current density in the HER. On the other hand, OER is an irreversible reaction and the current density is usually represented by the Butler-Volmer equation. However, the OER mechanism cannot be simply described because of its complexity, and the rate-determining step is still unclear. Hence, while the kinetic equation cannot be described, the water concentration term must be incorporated in the Butler-Volmer equation as a kinetic factor. Therefore, the water concentration has an asymmetrical influence on HER and OER.

Recently, a few papers have been published on the potential windows in concentrated electrolyte solutions. Suo et al. used a 'waterin-salt' solution (almost-saturated LiTFSA aqueous solution) and reported a wide potential window of ca. $3.0 \mathrm{~V},{ }^{15}$ They argued that the OER overpotential was probably a result of the reduced water activity at an inner Helmholtz layer that was increasingly populated by TFSA anions. In our study, a clear correlation between water concentration and potential window was observed (Fig. 4) despite the electrolyte salts. Yoshida et al. reported that solvation to $\mathrm{Li}^{+}$cation decreased the HOMO level of glyme molecules, and argued that the solution with a lower glyme/cation ratio showed a higher oxidation potential of glyme. ${ }^{28}$ However, in this study, we found that the water/cation ratio was not directly related to the potential windows, unlike such a solvated ionic liquid system. For example, $1 \mathrm{M}$ LiTFSA (water concentration: $49 \mathrm{M}$ ) and 7.8 $\mathrm{M} \mathrm{LiNO}_{3}$ (water concentration: $43 \mathrm{M}$ ) had a similar potential window, though the water/cation ratios were significantly different: 49 in $1 \mathrm{M}$ LiTFSA and 5.5 in $7.8 \mathrm{M} \mathrm{LiNO}_{3}$. As already shown in Fig. 1, the number of water molecules that were solvated to ions varied inversely with the water concentration. Hence, in this study, we show that the water concentration is important as a universal feature that determines the potential windows of aqueous solutions.

Furthermore, we performed cyclic voltammetry in sulfonic acid solutions with different water concentrations $(0.50$ and $10 \mathrm{M})$ to differentiate the effect of a local $\mathrm{pH}$ change from the effect of the water concentration. CVs of Pt are shown in Fig. 7. The onset potentials of HER were almost the same in the two solutions. However, the onset potential of OER in $10 \mathrm{M}$ solution was higher than that in $0.50 \mathrm{M}$ 
solution, similar to the results in neutral $\mathrm{pH}$ solutions as shown in Fig. 2. Here, in acid solutions, we have to consider the reaction potentials and kinetics of HER and OER. If we assume that HER on the Pt electrode surface is reversible,${ }^{25-27}$ the reaction occurs as follows;

$$
2 \mathrm{H}^{+}+2 \mathrm{e}^{-} \rightleftarrows \mathrm{H}_{2}
$$

When the fugacity of $\mathrm{H}_{2}$ is assumed to be equal to unity, the reaction potential $E_{\mathrm{HER}}$ is evaluated via the Nernst equation;

$$
E_{\mathrm{HER}}=E_{\mathrm{H}_{2} / \mathrm{H}^{+}}^{\circ}+\frac{R T}{2 F} \ln \left(a_{\mathrm{H}^{+}}\right)^{2}
$$

where $E_{\mathrm{H}_{2} / \mathrm{H}^{+}}^{\circ}$ is the standard reaction potential of Eq. 9. If migration is ignored, the current density $i$ can be described by the same Eq. 8 . Eqs. 8 and 10 do not include a term for the water concentration. Thus, the water concentration is not related to either the reaction potential or the current density of HER. Consequently, the onset potentials of HER were almost the same in solutions with different water concentrations. On the other hand, when the fugacity of $\mathrm{O}_{2}$ is assumed to be equal to unity, but the activity of water cannot be set to unity, the reaction potential $E_{\mathrm{OER}}$ is the same as in Eq. 6. In contrast to HER, there is a term for the activity of water. However, even if $a_{\mathrm{H}_{2} \mathrm{O}}$ changes by one order of magnitude, $E_{\mathrm{OER}}$ changes by only ca. $30 \mathrm{mV}$ at $25^{\circ} \mathrm{C}$. In Fig. 7, the difference in OER potential was at least ca. $100 \mathrm{mV}$, and if the $100-\mathrm{mV}$ shift is considered to be caused only by this reaction potential shift, $a_{\mathrm{H}_{2} \mathrm{O}}$ has to change by three orders of magnitude. Herein, we measured the vapor pressures of water for both 0.50 and $10 \mathrm{M} \mathrm{H}_{2} \mathrm{SO}_{4}$ solutions to estimate the change in the activity of water. The ratio of vapor pressures of water can be thought to be equal to the ratio of the activities of water. ${ }^{29}$ As a result, the ratio of vapor pressures of $0.50 \mathrm{M} / 10 \mathrm{M} \mathrm{H}_{2} \mathrm{SO}_{4}$ was 10 , which was almost the same as the value reported by Wilson et al., ${ }^{30}$ and therefore the large overpotential of OER in concentrated electrolyte solutions is mainly caused by the decrease in kinetic factors.

\section{Conclusions}

Potential windows of aqueous solutions were investigated systematically using various salts at different concentrations. Cyclic voltammetry measurements of Pt electrodes revealed two important points. First, the potential window in unbuffered neutral $\mathrm{pH}$ solution was broader than that in acidic/alkaline solutions. This expansion of potential windows can be explained by the shift in the reaction potential with local $\mathrm{pH}$ changes in the vicinity of the electrode. Second, the potential windows were not affected by electrolyte salts, but rather depended linearly on the water concentration. The difference for OER overpotentials was much larger than that for HER overpotentials. While HER overpotentials were derived from a local $\mathrm{pH}$ change, OER overpotentials were derived from both a reduced water concentration and local $\mathrm{pH}$ change. This study highlights the importance of these two main factors (water concentration and local $\mathrm{pH}$ change) in determining the potential windows of concentrated electrolyte solutions.

\section{Acknowledgment}

Part of this work was financially supported by CREST, JST (JPMJCR12C1) and JSPS KAKENHI grant Number 16H04216 and $17 \mathrm{H} 03113$

\section{ORCID}

Tomokazu Fukutsuka (D https://orcid.org/0000-0002-8731-9078

Kohei Miyazaki (D) https://orcid.org/0000-0001-5177-3570

\section{References}

1. S. Trasatti, J. Electroanal. Chem., 39, 163 (1972).

2. S. Trasatti, Electrochim. Acta, 29, 1503 (1984).

3. H. Kim, J. Hong, Park K.-Y., H. Kim, S.-W. Kim, and K. Kang, Chem Rev, 114 11788 (2014).

4. J. Liu, J. Hu, Q. Deng, J. Mo, H. Xie, Z. Liu, Y. Xiong, X. Wu, and Y. Wu, Isr J. Chem., 55, 521 (2015).

5. W. Li, J. R. Dahn, and D. S. Wainwright, Science, 264, 1115 (1994).

6. W. Li and J. R. Dahn, J. Electrochem. Soc., 142, 1742 (1995).

7. H. Wang, Y. Zeng, K. Huang, S. Liu, and L. Chen, Electrochim. Acta, 52, 5102 (2007).

8. G. Wang, L. Fu, N. Zhao, L. Yang, Y. Wu, and H. Wu, Angew. Chemie Int. Ed., 119, 299 (2007).

9. C. Wu, Z. Hu, W. Wang, M. Zhang, J. Yanga, and Y. Xie, Chem. Commun., 3891 (2008).

10. S. Liu, S. H. Ye, C. Z. Li, G. L. Pan, and X. P. Gao, J. Electrochem. Soc., 158, A1490 (2011).

11. H. Manjunatha, T. V. Venkatesha, and G. S. Suresh, J. Solid State Electrochem., 16, 1941 (2012).

12. M. Zhao, B. Zhang, G. Huang, H. Zhang, and X. Song, J. Power Sources, 232, 181 (2013).

13. W. Wu, S. Shanbhag, A. Wise, J. Chang, A. Rutt, and J. F. Whitacre, J. Electrochem. Soc., 162, A1921 (2015).

14. Z. Zhou, W. Luo, H. Huang, S. Huang, Y. Xia, N. Zhou, and Z. He, Ceram. Int., 43, 99 (2017).

15. L. Suo, O. Borodin, T. Gao, M. Olguin, J. Ho, X. Fan, C. Luo, C. Wang, and K. Xu, Science, 350, 938 (2015)

16. L. Suo, F. Han, X. Fan, H. Liu, K. Xu, and C. Wang, J. Mater. Chem. A, 4, 6639 (2016).

17. L. Suo, O. Borodin, W. Sun, X. Fan, C. Yang, F. Wang, T. Gao, Z. Ma, M. Schroeder, A. von Cresce, S. M. Russell, M. Armand, A. Angell, K. Xu, and C. Wang, Angew. Chemie Int. Ed., 55, 7136 (2016).

18. K. Miyazaki, T. Shimada, S. Ito, Y. Yokoyama, T. Fukutsuka, and T. Abe, Chem. Commun., 52, 4979 (2016).

19. K. Nakamoto, R. Sakamoto, M. Ito, A. Kitajou, and S. Okada, Electrochemistry, 85 179 (2017).

20. C. Wessells, R. Ruffo, R. A. Huggins, and Y. Cui, Electrochem. Solid-State Lett., 13, A59 (2010).

21. A. T. Kuhn and C. Y. Chan, J. Appl. Electrochem., 13, 189 (1983).

22. M. Wang, K. W. Feindel, S. H. Bergens, and R. E. Wasylishen, J. Power Sources, 195, 7316 (2010).

23. B. Liu and A. J. Bard, J. Phys. Chem. B, 106, 12801 (2002).

24. The Chemical Society of Japan, Handbook of Chemistry: Pure Chemistry, 5th ed., Vol. 2, p.332, Maruzen Pub., Tokyo (2004).

25. I. Katsounaros, J. C. Meier, S. O. Klemm, A. A. Topalov, P. Ulrich Biedermann, M. Auinger, and K. J. J. Mayrhofer, Electrochem. Commun., 13, 634 (2011).

26. M. Auinger, I. Katsounaros, J. C. Meier, S. O. Klemm, P. Ulrich Biedermann, A. A. Topalov, M. Rohwerder, and K. J. J. Mayrhofer, Phys. Chem. Chem. Phys., 13, 16384 (2011).

27. W. Sheng, H. A. Gasteiger, and Y. Shao-Horn, J. Electrochem. Soc., 157, B1529 (2010).

28. K. Yoshida, M. Nakamura, Y. Kazue, N. Tachikawa, S. Tsuzuki, S. Seki, K. Dokko, and M. Watanabe, J. Am. Chem. Soc., 133, 13121 (2011).

29. G. N. Lewis, Proc. Am. Acad. Arts Sci., 43, 259 (1907).

30. R. E. Wilson, J. Ind. Eng. Chem., 13, 326 (1921). 